\title{
Integrated geophysical survey to recognize ancient Picentia's buried walls, in the Archaeological Park of Pontecagnano - Faiano (Southern Italy)
}

\author{
Maurizio Fedi $\left({ }^{1}\right)\left({ }^{2}\right)$, Giovanni Florio $\left({ }^{1}\right)$, Bartolomeo Garofalo $\left({ }^{2}\right)$, Mauro La Manna $\left({ }^{2}\right)$, \\ Carmine Pellegrino $\left({ }^{3}\right)$, Amedeo Rossi $\left({ }^{3}\right)$ and Maria Grazia Soldovieri $\left({ }^{1}\right)$ \\ (') Dipartimento di Scienze della Terra, Università degli studi di Napoli «Federico II», Napoli, Italy \\ ${ }^{(}{ }^{2}$ Centro Regionale di Competenza per lo Sviluppo ed il Trasferimento dell'Innovazione Applicata ai Beni \\ Culturali e Ambientali INNOVA, Pozzuoli (NA), Italy
}

$\left(^{3}\right)$ Dipartimento di Beni Culturali, Laboratorio di Archeologia «M. Napoli», Università di Salerno, Fisciano (SA), Italy

\begin{abstract}
Research aims
There is no information on previous geophysical prospections carried out in the Archaeological Park of Pontecagnano-Faiano, in order to reconstruct the ancient settlement of Picentia, an Etrusco-Campanian and Roman settlement near Salerno (Southern Italy). Therefore, an integrated geophysical survey based on magnetic, geoelectric and ground-penetrating radar (GPR) prospections was executed in the Park. The methods provided a basic map of buried ancient structures at depth from 0.1-0.2 to about 1.5 meters. Magnetic data were processed analyzing the analytical signal of the vertical derivative of the measured gradient and this substantially reduced a strong fence effect. The results of the geophysical prospections showed archaeological structures located close to those discovered in the excavated areas. The shape of the anomalies are usually elongated with well-defined geometrical characteristics. Many anomalies are arranged along orthogonal directions and they are very coherent with the excavated structures, namely the quarters structures of the ancient Picentia.
\end{abstract}

Key words Ground-probing radar survey - Gradiometric survey - Geoelectrical survey - Archaeological buried structures

\section{Research aims}

The aim of this work was the recognition of buried structures in an archaeological park to extend the archaeological knowledge of the ancient settlement. This was proved by a visible

Mailing address: Dr. Maurizio Fedi, Dipartimento di Scienze della Terra, Università degli Studi di Napoli «Federico II», Largo San Marcellino 10, 80138 Napoli, Italy; e-mail: fedi@unina.it wide excavation and by further minor documented excavations successively recovered in 1970. The geophysical methods disclosed a geometrical setting of the buried structures around the major and minor excavations. In particular, the GPR survey was executed near a major excavation and identified a prolongation of the quarter's structures of the Picentia ancient city in the major excavation. These results are very useful for archaeologists, as the previous knowledge was based on the hypothesis that the quarter was the only one visible in the major excavation along the Decumanus. Moreover, the presence of the detected buried structures demonstrates the absence of the Cardo (NE/SW road) in the previously presumed position. 


\section{Introduction}

In recent decades, non-destructive integrated geophysical prospecting methods have been increasingly used for the investigation of archaeological sites (Neubauer et al., 1997; Neubauer, 2001; Eppalbaum et al., 2001; Hounslow et al., 2002; Piro et al., 2003). The combination of several geophysical prospecting methods offers very high-resolution sounding capability with detection of features of the order of a few tens of centimetres thickness at ranges of several metres. This paper describes the results of an integrated geophysical investigation based on ground-probing radar (GPR), geoelectrical (ERT) and magnetic surveys in the Archaeological Park of Pontecagnano-Faiano, located near Salerno in Southern Italy. The survey was realized using the geophysical instrumentation available at the Archaeogeophysical Mobile Laboratory of the Centro Regionale di Competenza INNOVA.

Previous archaeological excavations (1971 and 1989) disclosed a part of the ancient city settled along the main road (Decumanus) of Picentia. The excavations yielded information on the concurrent superposition of ruins from several periods of different age, spanning an interval of about 1000 years. The settlement of Pontecagnano (fig. 1) developed from IX century $\mathrm{BC}$ to V-VI century AD, the most important period being the Etrusco-Campanian period (IX-IV century BC). The ancient town occupied the highest part of a travertinic platform, delimited by two streams, the Picentino to the west and the Frestola to the east. The main topographical feature of the Etrusco-Campanian settlement is the position of the necropolis, situated in the inhabited area (Cerchiai, 1995). The ruins visible in the major excavation are referred to Picentia village, founded by Romans in 268 BC (Cinquantaquattro, 2000; Giglio, 2001). The Roman «colonia» was laid out according to a general plan: the buildings were situated in rectangular blocks divided by a NE/ $\mathrm{SW}$ road (cardo) and a NW/SE road (decu-

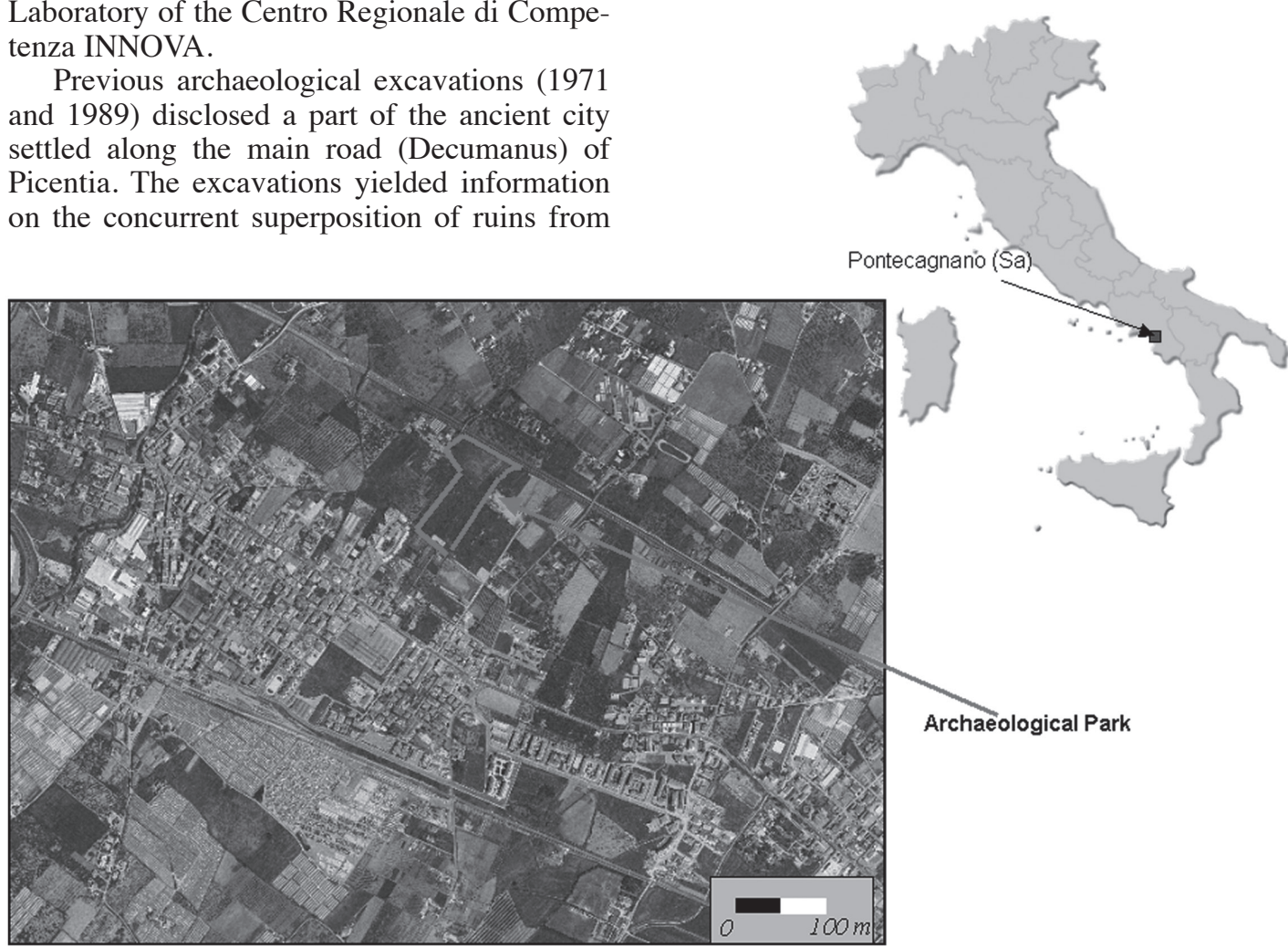

Fig. 1. The site of the Pontecagnano-Faiano Archaeological Park, near Salerno in Southern Italy. 
manus). The main road «Decumanus» was used in Roman Imperial times when new buildings were built according the NE/SW orientation of ancient plan (Strøm, 1993). Several building phases and walls often run with the same orientation.

Starting from the short archaeological description and the results of excavations, we devised an integrated geophysical survey to detect buried structures (walls, canals, etc.) of the ancient Pontecagnano and Picentia settlements. In particular the aim of this work regarded the definition of the eastern boundary of the excavated quarter, visible in the major excavation covered by a metallic roof, and the continuation towards northwards of the buried structures between this and the other digs.

\section{Magnetic, geoelectrical and GPR surveys}

The area of study is located at the NW edge of the alluvial zone of the Sele Plain. Outcropping terrains in this area are marine sands along the coast and fenny-fluvial and travertine deposits along the foothill zones and carbonate slopes. Pontecagnano - Faiano site is characterized by a thick travertine layer of Pleistocene age with a not fully developed soil layer above, due to debris supplies. Travertine plates and/or volcanic and alluvial soils intercalate these soils.

In the Archaeological Park of Pontecagnano-Faiano several structures are visible in three excavations. The largest one has an L-shape 50 $\mathrm{m}$ long and $20 \mathrm{~m}$ wide. The walls constructed with travertine blocks (carbonate) are about 50 $\mathrm{cm}$ thick while the canals present a thickness of 20-25 cm. In the L-shape excavation, unfortunately covered by a metallic shed, SW tanks with dimensions of $1 \mathrm{~m} \times 2 \mathrm{~m}$, associated with a complex system of water supply and buildings are present. The supposed features of the possible targets led us to carry out the geophysical survey in two zones, indicated by 1 and 2 in the fig. 2a. Resistivity, gradiometric and GPR methods were executed in a central sector of $25 \times 70 \mathrm{~m}^{2}$ of the Park, between two minor excavations (zone 2). A GPR survey was also carried out in zone 1 , measuring $14 \times 14$ $\mathrm{m}^{2}$, located close to the main excavated area which was covered by a metallic shed (outlined by a red line in the fig. 2a). The archaeological structures unearthed in this excavation represent the foundation of a neighborhood of the ancient city settled along the main road (Decumanus) of Picentia (III century BC). In 1970, archeologists excavated a trench, currently
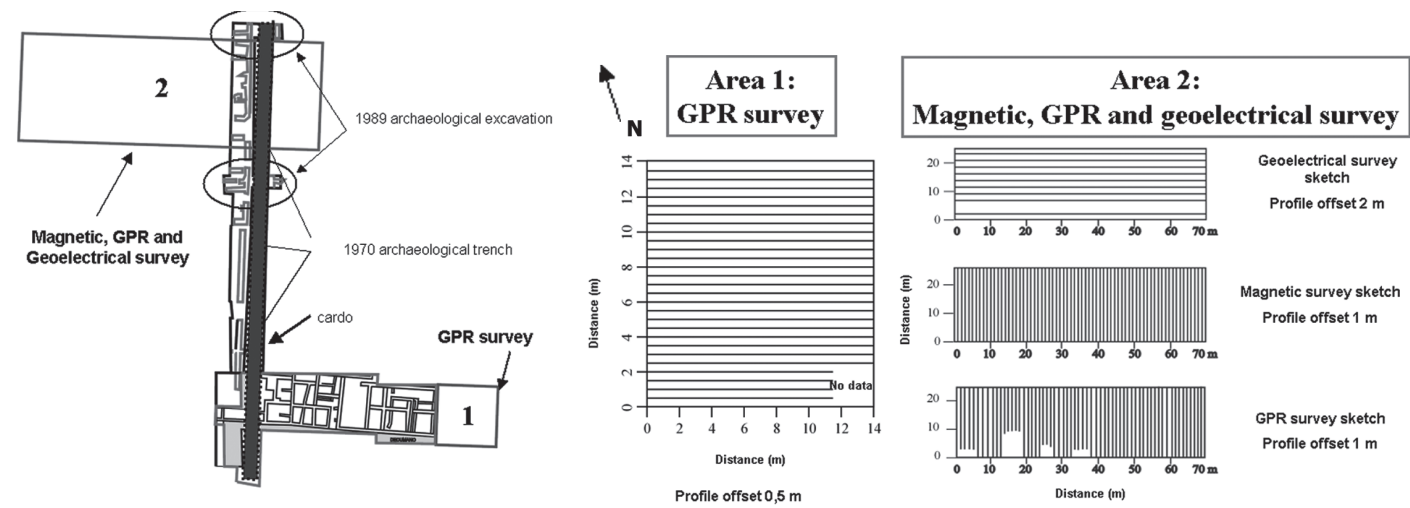

(a)

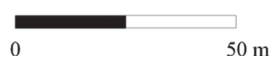

(b)

Fig. 2a,b. Sketch map of the archaeological park with the localization of the geophysical survey areas a); geophysical survey sketch of the areas $b$ ). 
filled, discovering the buried structures shown in fig. 2a. This trench was excavated to reveal this Cardo, which is now observable in the NW side of the major excavation.

A GSM 19 V6 Overhauser gradiometer was utilised to carry out the geomagnetic survey (fig. 2b, magnetic survey sketch). This instrument measures the magnetic field at two sensors spaced $0.5 \mathrm{~m}$ with a distance of the upper sensor to the surface of about $1.50 \mathrm{~m}$ and $1 \mathrm{~m}$ for the lower one. This gradiometric configuration yields measurements of the gradient of the magnetic field at an altitude from the soil of about $1.25 \mathrm{~m}$. Our choice of a relatively high elevation of the first sensor respect to the soil was due to the necessity of attenuating, just during survey, the strong cultural noise relative to many very small metallic objects scattered on the soil. This effects masked or distorted the shapes of the gradiometric anomalies characterized by small amplitude (1 - $10 \mathrm{nT})$ linked to buried archaeological structures. The GSM 19 records the Earth's magnetic field with $0.01 \mathrm{nT}$ resolution, and $0.2 \mathrm{nT}$ accuracy over its full temperature range. From the difference of two measurements (nT) an approximation of the vertical component of the field gradient is computed by

$$
\frac{\Delta T}{5.0} n T / m
$$

The geomagnetic data were collected continuously versus time using a sample rate of 0.5 seconds within regular grids with a $1 \mathrm{~m}$ spacing offset between the profiles. The choice of the $1 \mathrm{~m}$ spacing offset was forced by logistic conditions. In fact, the presence of brushes and a small fruit tree prevented a higher spatial resolution. The pre-processing of vertical magnetic gradient data (fig. 3a) regarded the attenuation of noisy contribution as spikes, stripes and the so called zigzag effect (Ciminale and Loddo, 2001). In order to reduce the effect of a metallic fence that surrounds the entire archaeological park, a map of the second vertical derivative of the magnetic field was also computed (fig. 3b). Different dipolar anomalies are evident in this map in a range of $-3 \div 3 \mathrm{nT} / \mathrm{m}^{2}$. The analytical signal (AS) of such anomalies was then com- puted (fig. 3c) since AS anomalies are simpler to interpret with respect to those of the magnetic field (or of its gradient). They are, in fact, not structured in a dipolar shape but just in highs. This operation allows an easier identification of anomalies linked to different structures of archaeological interest. In fact, elongated structures generate extended AS anomalies with a shape easily attributable to walls and/or channels.

An IRIS Syscal PRO georesistivimeter was used to carry out the geoelectrical survey. It was executed to integrate magnetic measurements for a suitable interpretation of the previously detected anomalies. In fact, «soil-wall» gradiometric anomalies may be correlated with resistivity ones, due to the contrast between the soil with a good conductivity and the low conductivity of buried structures (generally wall or part of them). The ERT survey was carried out with a 10 channel resistivity and IP - meter with an automatic injection ranging system. Logistic difficulties due to the presence of brushes and a small tree fruit and the idea to execute the resistivity profiles orthogonal to magnetic ones guided the resistivity survey as follows. The data were collected along 11 profiles 70 meter long, $2 \mathrm{~m}$ spaced, with a $1 \mathrm{~m}$ inter-electrodes distance using a dipole-dipole array (fig. 2b, geolectrical profiles sketch). This geometry was established to detect structures (tanks) with dimensions ranging from 1 to 2 meters. The main feature of a dipole-dipole array consists in the variable distance between potential and current electrodes, following entire multiples of the fixed inter-electrodes spacing. The reciprocal positions of the electrodes are changed along the fixed array. Resistivity measurements were elaborated with an inversion algorithm proposed by Loke and Barker (1996). The results of the inversion with a depth ranging from $0.75-2.36 \mathrm{~m}$ are shown in fig. 4 . Several resistivity anomalies were detected, probably connected to the buried structures. The resistivity values are in the range allowed for typical archaeological remains.

The GPR survey was performed using a GSSI SIR-3000 equipped by different frequency antennae. Due to the analysis of the remains in the large excavations, we expected 
(a)

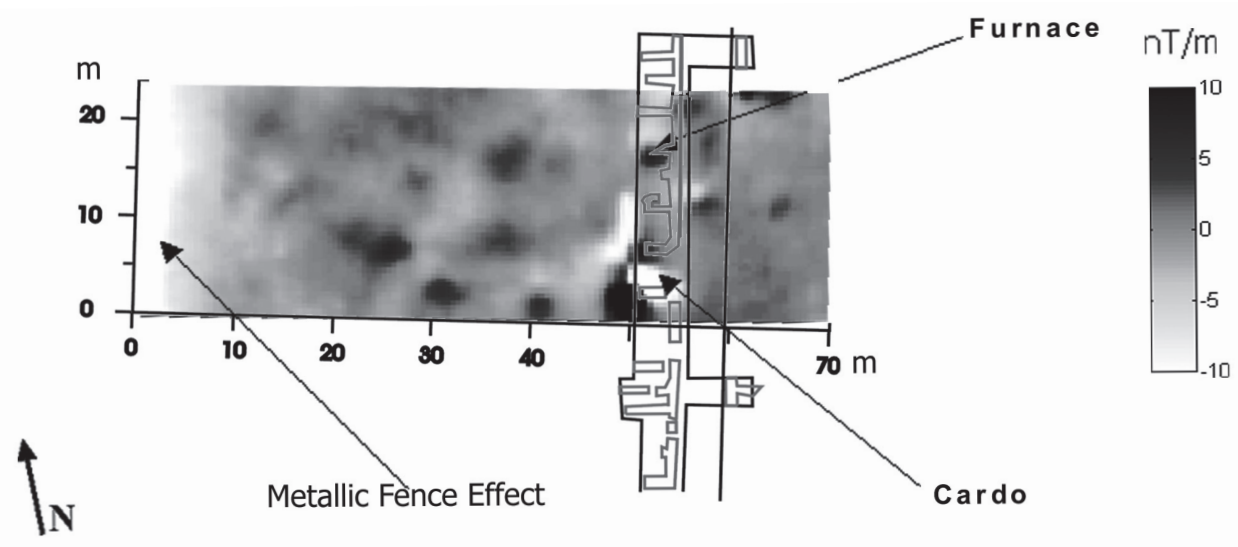

(b)

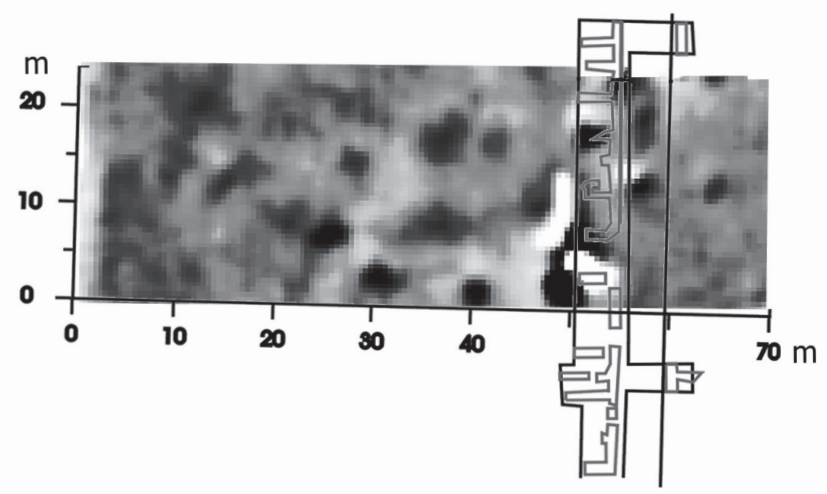

(C)
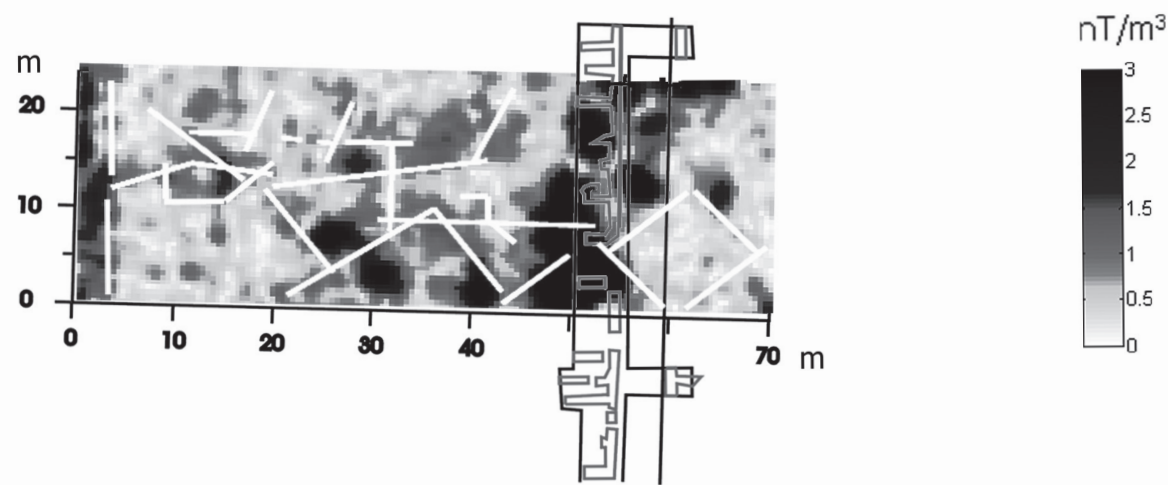

Fig. 3a-c. Map of the gradient of the magnetic field measured in a sector of $25 \times 70 \mathrm{~m}^{2}$ of the Park between two minor excavations a) Second vertical derivative of the magnetic field $b$ ) The metallic fence effect is reduced thanks to the numerical derivation and a more detailed pattern of the main anomalies is also observed. Analytical signal c) of the second vertical derivative of the magnetic field. The metallic fence effect is even more reduced, due to a further numerical derivation. White bold lines indicate highs linked to the main anomalies. 

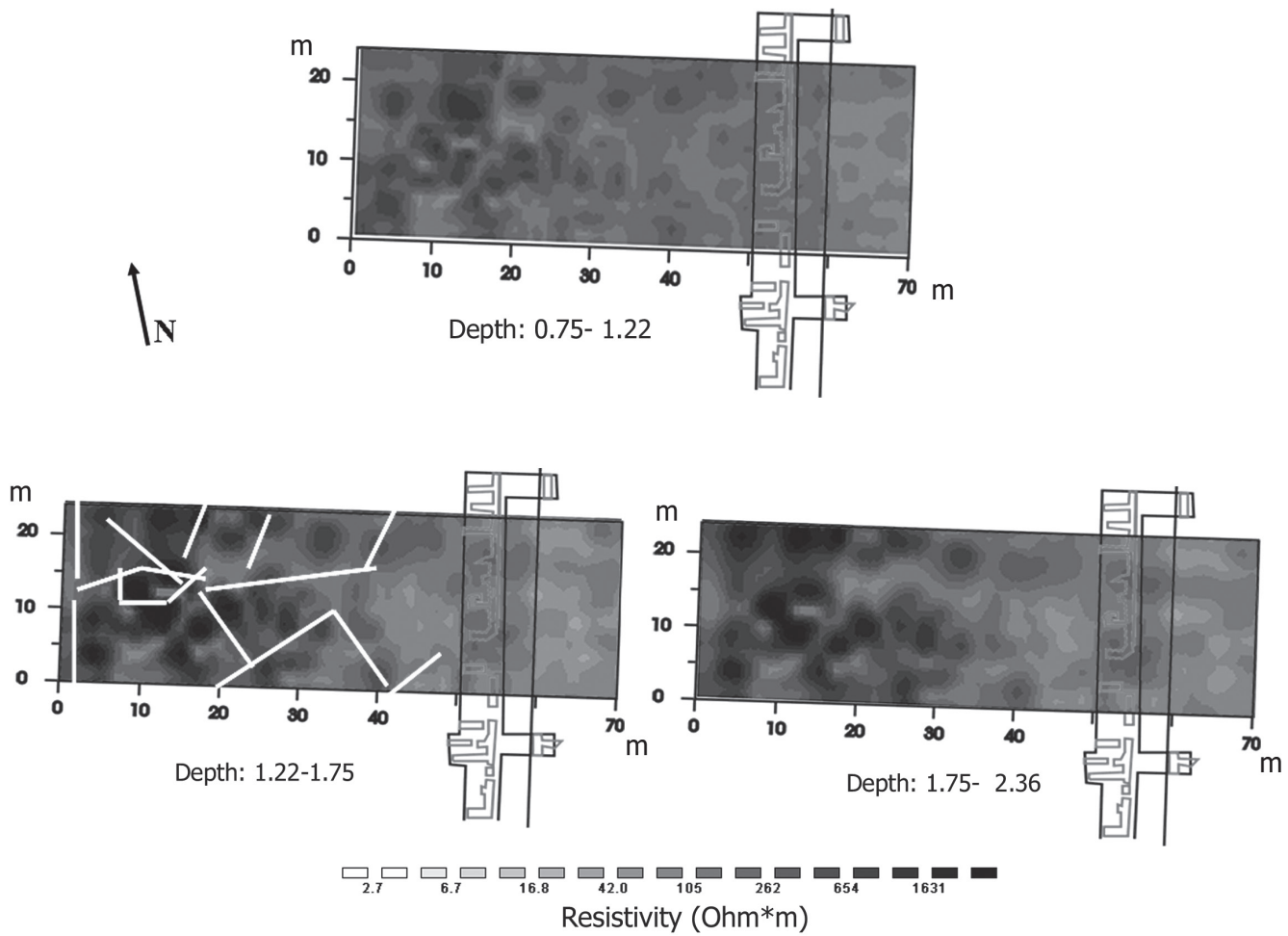

Fig. 4. Results of the inversion of geoelectrical data at depths ranging from 0.35 to $2.36 \mathrm{~m}$. They are concentrated in the western sector of the map. The main resistivity anomalies are indicated with white bold lines. In the eastern sector SW resistivity anomalies are correlated with the superposition of the structures excavated in the archaeological 1970 trench.

to recognize archaeological structures at a depth of about $0.7-1 \mathrm{~m}$, with a thickness of $0.7-1 \mathrm{~m}$. Better results were obtained using a $400 \mathrm{MHz}$ mono-static one, due to the actual depth and size of the buried features. Data were collected along $1 \mathrm{~m}$ spaced parallel lines in the same direction of the magnetic survey (fig. 2b, GPR profiles sketch). Measures were obtained along profiles covering the same area of magnetic survey (see above), with 50 scans per meter. The data were processed to obtain images of the structures present at several depths into the subsoil (time-slices). The main steps for the post-processing of the GPR datasets were: corrections for topographical variations, band-pass frequency filtering, background removal, stacking for time-slices adjustments.
Sequences of trace plots in two-dimensional profiles are sometimes difficult to analyse, so it can be difficult to identify EM anomalies linked to buried structures. We considered a velocity of $0.08 \mathrm{~m} / \mathrm{ns}$ for the propagation of waves in the subsoil, after the analysis of several diffraction hyperbolas. The maps allowed the visualization of the settlement of the ground at different reflection time levels, transformed with the relation depth $=$ time/velocity, at a specified depth . Time-slices referred to a depth ranging from 0.6 $-2.2 \mathrm{~m}$ are shown in fig. 5 .

A $400 \mathrm{MHz}$ mono-static antenna was used for the acquisition of data in the sector close to the main excavation, along $0.5 \mathrm{~m}$ spaced parallel lines (fig. 2b, GPR profiles sketch). GPR data were processed to obtain time-slices. The main steps for the post-processing the EM data- 

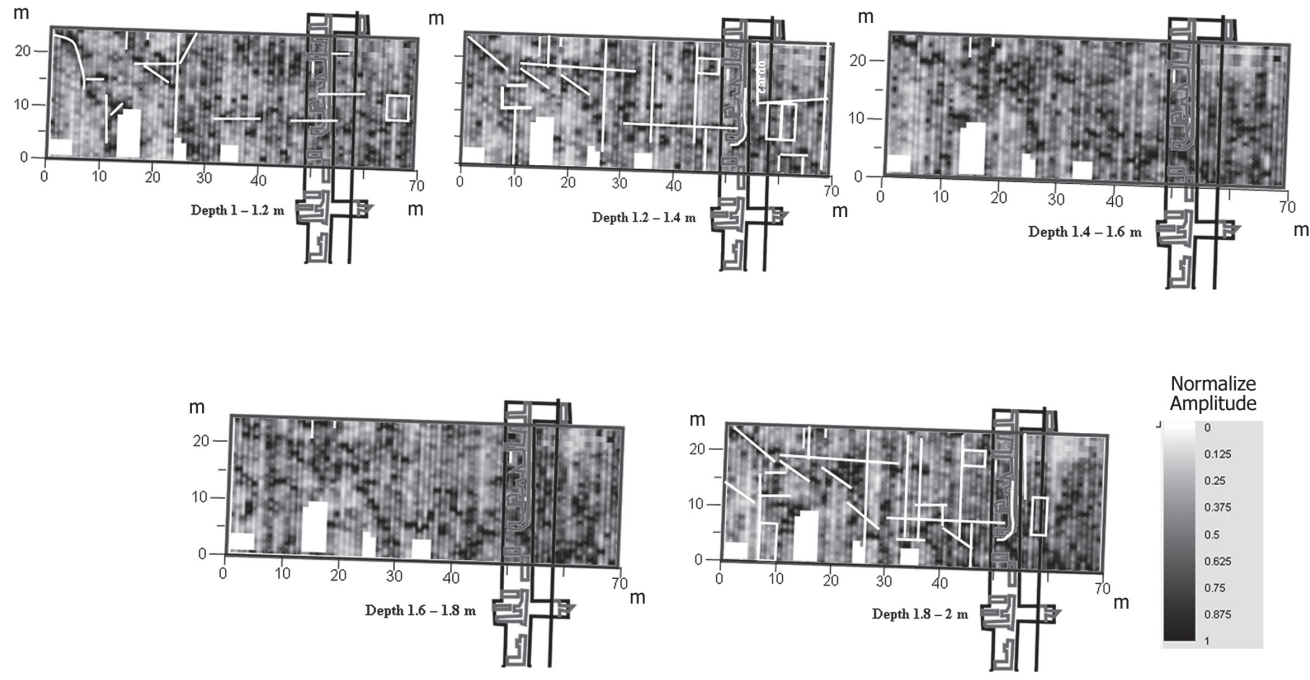

Fig. 5. GPR time-slices referred to a depth ranging from 0.6 to $2.2 \mathrm{~m}$. Time slices were computed along regular grid. Many elongated anomalies cross each other assuming a rectangular shape. These anomalies show a N-S and E-W behavior. Slices referred to a depth ranging from 1.4-2.2 m show a NW-SE and SW-NE behavior.

sets are the same of those used for the elaboration of data collected for the first sector. Figure 6 shows the time-slices obtained for a depth ranging from $0.2 \mathrm{~m}$ to $1.95 \mathrm{~m}$.

\section{Discussion}

The geophysical survey detected different interesting anomalies of possible archaeological interest. The analytic aignal (AS) (Roest et al., 1992) of the second vertical derivative of the magnetic field (fig. 3c) shows several highs due to the presence of buried structures. In particular, intense highs are located between $50 \mathrm{~m}$ and $60 \mathrm{~m}$ along the $\mathrm{x}$ - axis in correspondence with the buried walls discovered during the 1970 excavation (Cinquantaquattro, 2000; Giglio, 2001). Other geomagnetic anomalies are located along the western side of the map, in good agreement with GPR and geoelectrical anomalies (see figs. 3, 4 and 5). Note that most of geophysical anomalies from each of the three different methodologies are well correlated. Figure 4 shows the resistivity anomalies located at a depth ranging from $1.22 \mathrm{~m}$ to $1.75 \mathrm{~m}$, in the western side of the map. The resistivity values are typical of buildings structures. EM anomalies located at the same position and at the same depth as geoelectrical anomalies occur in the GPR time-slices (see fig. 5). All anomalies are shown in white bold lines.

In the zone near the main excavation the GPR survey shows an impressive continuation of the foundation of a quarters of ancient Picentia.

Figure 6 shows several time-slices for different depths of investigation ranging from 0.2 $\mathrm{m}$ to $1.95 \mathrm{~m}$.

Looking at the depth slice from $0.55 \mathrm{~m}$ to $1.6 \mathrm{~m}$, it is possible to identify SW elongated GPR anomalies, which, as a matter of fact, have the sense of continuing the structures observed in the adjacent excavation. In fact, the anomalies have dimensions comparable with those of a room. These results are validated by examination of the depth of the unearthed structures: the top of the foundations is identified at $0.9 \mathrm{~m} \mathrm{-}$ $1.0 \mathrm{~m}$. In the depth interval from $1.25 \mathrm{~m}$ to 1.6 $\mathrm{m}$, the effect of the presence of the «Decumanus» is also seen. It is possible to follow the continuation of the main ancient road through- 


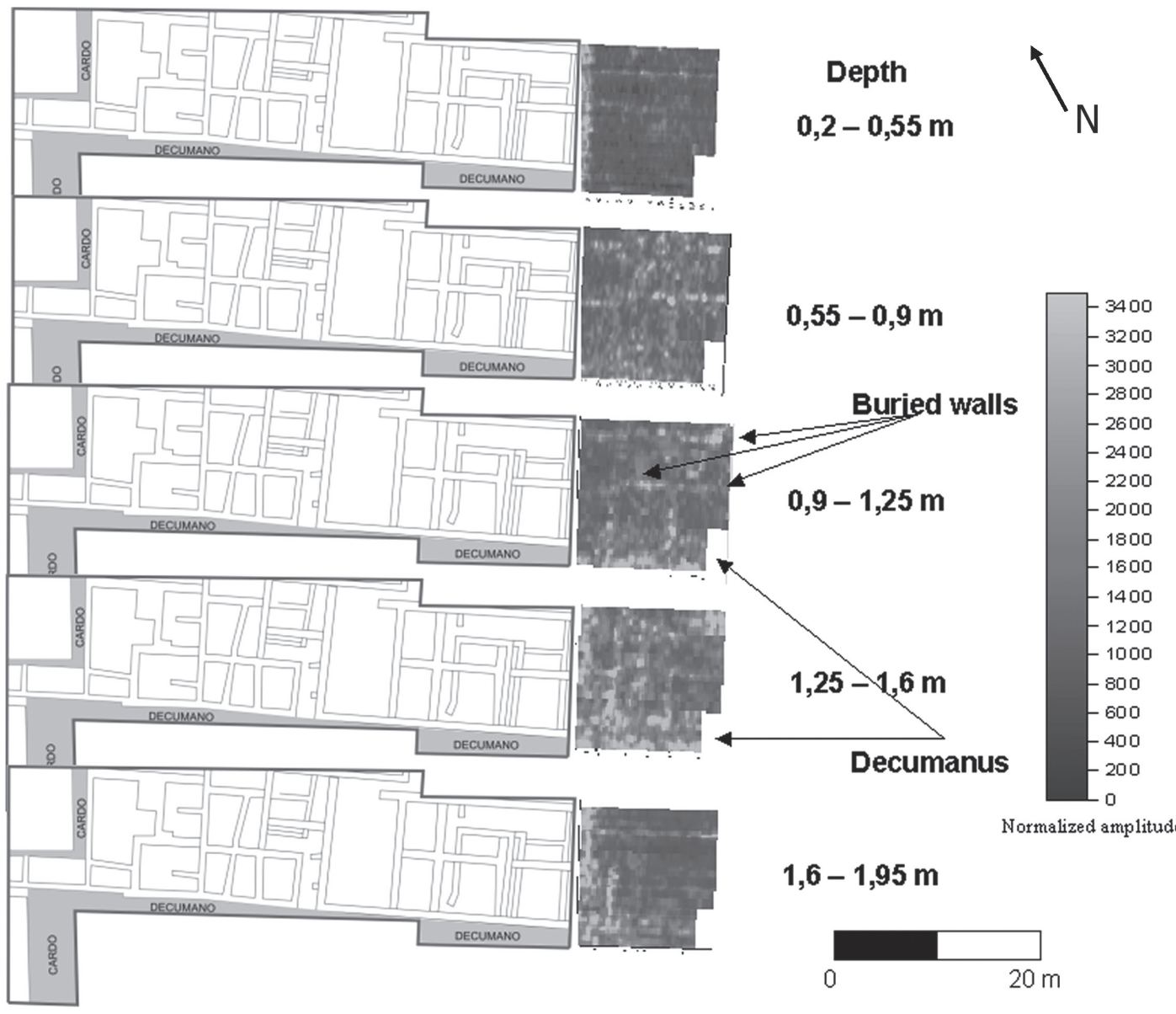

Fig. 6. GPR time-slices obtained for a depth ranging from $0.2 \mathrm{~m}$ to $1.95 \mathrm{~m}$ in area 1 . SW elongated anomalies at depths from $0.55 \mathrm{~m}$ to $0.9 \mathrm{~m}$ seem continuing the structures of the adjacent excavation. These ones are well visible down to $1.6 \mathrm{~m}$ depth. The depth slices relative to the depth of $1.25 \mathrm{~m} 1.6 \mathrm{~m}$ disclose the effect of the presence of the «Decumanus».

out the GPR survey in the bottom part of the slice. Definitely, the most important result of the GPR survey regards the extension of the neighborhood of Picentia and «Decumanus» farther from the L-shape excavated area.

\section{Conclusions}

An integrated geophysical survey allowed us to define the eastern boundary of the exca- vated quarter disclosed by the major excavation in the area of the Archaeological Park of Pontecagnano-Faiano. So, archaeologists can easily perform a continuation of the buried structures between this and other small excavations.

The prolongation of the ancient city's structures continues next to excavated structures visible in the major archaeological test. These results are very useful for archaeologists as the previous knowledge was based on the hypothesis that the quarter was only that visible in the major excava- 
tion along the Decumanus. Moreover, such identification of buried structures demonstrates the absence of the cardo (NE/SW road) in the previously presumed position. GPR and ERT description shows that the interesting buried structures are in the $1.22 \mathrm{~m}$ to $1.75 \mathrm{~m}$ depth range. These features agree with the direction of structures unearthed in the 1970 trench. Anomaly shapes are usually elongated with well-defined geometrical characteristics. Many anomalies are arranged orthogonally to each other looking like walls of buried rooms.

The results of the integrated geophysical prospections encourages geophysicists and archaeologists to further explore the entire Archaeological Park to obtain a wider reconstruction of the buried structures.

\section{REFERENCES}

CerChiai, L. (1995): I Campani, Milano.

Ciminale, M. and M. LodDo (2001): Aspects of magnetic data processing, Archaeological Prospections, 8, 239246, doi: 10.1002/arp.172.

Cinquantaquattro, T. (2000): Pontecagnano (SA): saggi stratigrafici nell'abitato antico, Bollettino di Archeologia, 28-30 (1994), 121 e 171.

Eppelbaum Lev, V., E. Khesin Boris and E. ItKis Sonya (2001): Prompt Magnetic Investigations of Archaeological Remains in Areas of Infrastructure Develop- ment, Israeli Experience, Archaeological Prospection, 8, 163-185, doi: 10.1002/arp. 167.

Giglio, M. (2001): Picentia, fondazione romana?, AION, 8 (n.s.), 119-131.

Hounslow, M.W. and P. NeIL Chroston (2002): Structural Layout of the Suburbs of Roman Butrint, Southern Albania: Results from a Gradiometer and Resistivity Survey, Archaeological. Prospection, 9, 229-242-

LoKe, M.H. and R.D. BARKER (1996): Rapid leastsquares inversion of apparent resistivity pseudosections by a quasi-Newton method, Geophysical Prospecting, 44.

Neubauer, W., A. Eder-Hinterleitner, S. Seren and P. Melichar (1997): Georadar in the Roman Civil Town Carnuntum, Austria: An Approach for Archaeological Interpretation of GPR Data, Archaeological Prospection, 9, 135-156, doi: 10.1002/arp.183.

Neubauer, W. (2001): Magnetische Prospektion in der Archaologie, Mitteilungen der Prahistorischen Kommission, 44, Osterreichische Akademie der Wissenshaften, Wien.

Piro, S., D. GoOdman and Y. Nishimura (2003): The Study and Characterization of Emperor Traiano's Villa (Altopiani di Arcinazzo, Roma) using High-resolution Integrated Geophysical Surveys, Archaeological Prospection, 10, 1-25, doi: 10.1002/arp.203.

Roest, W.R, J. Verhoef and M. Pilkington (1992): Magnetic interpretation using the $3 \mathrm{D}$ analytic signal, Geophysics, 57 (1), 116-125.

Strøm, I. (1993): Pontecagnano-Picentia. A. Hellenistic Town in the Former Etruscan Campania. The Danish Escavation, Acta Hyperborea, 5, 107-126.

(received November 26, 2007; accepted September 23, 2008) 